\title{
The effect of carbonate rock wettability on the performance of low salinity waterflooding: an experimental approach
}

\author{
Abdulrazag Zekri ${ }^{1} \cdot$ Hildah Nantongo $^{1}$ (D) $\cdot$ Fathi Boukadi ${ }^{2}$
}

Received: 21 January 2021 / Accepted: 16 September 2021 / Published online: 26 September 2021

(c) The Author(s) 2021

\begin{abstract}
While the "low salinity waterflooding" (LSWF) has been praised for enhancing oil recovery from different core rocks, the performance of the technique in different wettability environments remains unclear. The consensus is that LSWF does not work well in water-wet carbonate oil reservoirs. The main research objective was to determine the effect of LSWF on the displacement efficiency (DE) in different wettability environments. Carbonate core flooding experiments on rocks with different wettabilities were performed at in-situ reservoir conditions using seawater as a "base water". Seawater was sequentially diluted 10 to 50 times and spiked 2 and 6 times with sulfate. Following sequential flooding with four different waters, the DEs were measured for different wettabilities. Five different sequential brine floodings were performed on carbonate rocks. Results indicated that optimum low salinity water is a function of system wettability. Seawater $(\approx 50,000 \mathrm{ppm})$ is the optimum brine for oil-wet and intermediate-wettability systems. Sequential flooding consisting of seawater followed by diluted seawater in a water-wet system yielded the highest DE of $88 \%$. Besides, low-salinity brine followed by sulfate performed better in a water-wet environment than in oil- and intermediate-wettability systems.
\end{abstract}

Keywords Low-salinity water $\cdot$ Wettability alteration $\cdot$ Modified water $\cdot$ Core flooding $\cdot$ Sequential flooding $\cdot$ Displacement efficiency

\section{Introduction}

Incremental oil recovery has been attributed to wettability reversal in low-salinity water flooding (LSWF). In fact, it is currently widely accepted that wettability reversal has yielded lower contact angles in water. In fact, Mahani et al. (2015) observed lower contact angles for undiluted and diluted seawater while Agbalaka et al. (2008) reported that different cores became more water-wet when flooded with low salinity brine. In addition, Yousef et al. (2012) performed LSWF measurements under reservoir conditions and

Hildah Nantongo

nhildah89@gmail.com

Abdulrazag Zekri

a.zekri@uaeu.ac.ae

Fathi Boukadi

fathi.boukadi@louisiana.edu

1 Department of Chemical and Petroleum Engineering, United Arab Emirates University, P.O. Box 15551, Al-Ain, UAE

2 Department of Petroleum Engineering, University of Louisiana, Lafayette, LA, USA demonstrated that diluted seawater could enhance water-wet properties of reservoir rocks. Through history matching and based on core flooding experiments originally reported by Chandrasekhar (2013), Al-Shalabi et al. (2014) also investigated production mechanisms under LSWF for carbonate rocks. In all these experiments, wettability alteration was shown to be a dominant mechanism under LSWF (Agbalaka et al., 2008; Al-Shalabi et al., 2014; Yousef et al. 2012). In other studies, reported by Zaeri et al. (2018), Amott (imbibition) tests, that were done on carbonate rock materials from Iranian petroleum reservoirs, yielded an optimum degree of dilution that led to maximum recovery.

Furthermore, LSWF-instigated incremental oil recovery may also be attributed to salinity gradients. Cumulative salinity gradients associated with injection of waters of different salinities may lead to diffusiophoresis (joining) and mobilization of the isolated oil drops (Prieve and Roman 1987). Zaeri et al. (2018) have also confirmed that injecting batches of water with different salinities facilitates ion transport between the rock surface and brine, thus leading to wettability alteration and improved oil recovery. Additionally, it has also been reported that temperature does affect 
wettability alteration. For example, in studies performed by Schembre et al. (2006), the Amott wettability indices for carbonate and sandstone cores were measured. Authors indicated that increased temperature could change rock wettability from low- to intermediate- to strong-water wetness. Further still, Gomari and Hamouda (2006) have also reported that the increase in temperature does make calcite surface more water-wet thereby contributing to incremental oil recovery. In another study, Khilar and Fogler (1983) stated that a critical brine concentration of approximately 0.4 by wt $\% \mathrm{NaCl}$ brines enhanced oil recovery in sandstones. According to these authors, decreasing the concentration below this value triggered clay destabilization and formation damage. In another report, a moderate increase in oil recovery was observed during the injection of low-salinity water with $0.2-0.5$ by wt\% $\mathrm{NaCl}$ (Morrow and Buckley, 2011). During the same year, Alagic and Skauge (2011), developed a correlation relating fine particle migration and wettability. These authors also indicated that fine particle migration did not take place during LSW injection in aged cores, but happened when unaged water-wet cores were used. This finding is in agreement with results reported by Mungan (1965) and Clementz (1982). In addition, Chandrashegaran (2015) concluded that an injected water salinity of 0.2 by wt $\%$ is the optimal concentration for most rock types.

Wettability alteration is not a separate mechanism; it is also caused by other micro-scale mechanisms (Katende and Sagala, 2019). These are surface ion exchange, surface charge change, double-layer expansion, and mineral dissolution. In this study, a number of other chemical/physical wettability reversal mechanisms, that may hypothetically increase oil recovery and displacement efficiency, were evaluated.

\section{Material and methods}

\section{Fluids}

A crude oil with an API gravity of $39.5^{\circ}$ was filtered through a 5-mm filter paper prior to any laboratory application. No asphaltene precipitation was observed during the storage. The crude oil had an acid number of $0.07 \mathrm{mg} \mathrm{KOH} / \mathrm{g}$. The number was measured using the ASTM D664 standard titration procedure. The oil viscosity was measured using a rolling ball viscometer at $20^{\circ} \mathrm{C}$ and the measured value was $2.93 \mathrm{cP}$.

Eleven brines were used in the core flooding phase of this project. These brines include the formation water $(\mathrm{FW})$, the water that is currently injected in the reservoir (IW) and seawaters (SW) with different salinity and sulfate concentrations. Table 1 presents the composition of the waters utilized in this project. Diluted seawater solutions are classified as
Table 1 The composition of diluted and spiked brines used in the study

\begin{tabular}{llllll}
\hline Ion & SW & SW/10 & SW/50 & SW $\times 2$ SO4 & SW $\times 6$ SO4 \\
\hline Calcium & 690 & 69 & 13.8 & 690 & 690 \\
Sodium & 18,680 & 1868 & 373.6 & 21,748 & 17,475 \\
Magnesium & 2132 & 213.2 & 42.64 & 2132 & 2132 \\
Potassium & 672 & 67.2 & 13.44 & 672 & 672 \\
Bromide & $<0.1$ & $<0.1$ & $<0.1$ & $<0.1$ & $<0.1$ \\
Zinc & $<0.1$ & $<0.1$ & $<0.1$ & $<0.1$ & $<0.1$ \\
Phosphate & $<0.1$ & $<0.1$ & $<0.1$ & $<0.1$ & $<0.1$ \\
Chloride & 27,370 & 2737 & 547.4 & 17,450 & 15,450 \\
Sulfate & 3944 & 394.4 & 78.88 & 5916 & 17,748 \\
Bicarbonate & 123 & 12.3 & 2.46 & 123 & 123 \\
Nitrate & 0 & 0 & 0 & 0 & 0 \\
Strontium & 0 & 0 & 0 & 0 & 0 \\
Carbonate & 0 & $<0.1$ & $<0.1$ & $<0.1$ & $<0.1$ \\
TDS (MG/L) & 53,611 & 5361.1 & 1072.22 & 48,731 & 54,290 \\
\hline
\end{tabular}

follows: SW/10 is a ten-time diluted solution, SW/50 is a 50-time diluted solution. On the other hand, spiked solutions are classified as follows: $2 \mathrm{SO}_{4}$ is a $\mathrm{SW}$ with a sulfate concentration that has been spiked twice and $6 \mathrm{SO}_{4}$ refers to a SW with a sulfate concentration that has been spiked six times.

The sequential core flooding experiments for intermediate-wettability oil reservoirs, conducted by Zekri et al. (2020), were repeated in this study in oil- and water-wet environments in order to assess the effect of carbonate rock wettability on the performance of low-salinity flooding. This study mainly focused on testing the seawater and its dilutions at different sulfate spiking. The formation water has a TDS of 157,488 with a density of 1.1074 and a viscosity of $1.2482 \mathrm{cp}$ at ambient conditions. The high salinity water currently being injected in the reservoir under study has a TDS of $258,250 \mathrm{mg} / \mathrm{l}$ with a density of $1.1639 \mathrm{mg} / \mathrm{l}$ and a viscosity of $1.75 \mathrm{cp}$ at ambient conditions. The brines used in the flooding were categorized, based on their dilution and sulfate spiking, into seven different sets. Brines' compositions are presented in Tables 1 and 2.

\section{Core samples}

Ten limestone carbonate core samples were selected from many core plugs. These Limestone core samples had an approximate diameter of $1.5^{\prime \prime}$ and were gray in color. Five were used in the water-wet experimental runs and five in the oil-wet runs. All the core plugs for water-wet reservoir experiments were saturated with formation brine then aged for a minimum of three weeks in formation water prior to the sequential LSWF. The selected core samples for the oilwet experiments were initially flooded with formation brine, then flooded with Asab (AS) crude oil and aged in the same 
Table 2 The composition of diluted brines and their spiked solutions used in the study

\begin{tabular}{|c|c|c|c|c|c|c|}
\hline Ion & $\mathrm{SW} / 10 \times 2 \mathrm{SO} 4$ & $\mathrm{SW} / 10 \times 6 \mathrm{SO} 4$ & $\mathrm{SW} / 50 \times 2 \mathrm{SO} 4$ & $\mathrm{SW} / 50 \times 6 \mathrm{SO} 4$ & IW & FW \\
\hline Calcium & 69 & 69 & 14 & 14 & 19,763 & 13,840 \\
\hline Sodium & 1265 & 1792 & 1764 & 2836 & 72,237 & 44,261 \\
\hline Magnesium & 213.2 & 213.2 & 43 & 43 & 3569 & 1604 \\
\hline Potassium & 67.2 & 67.2 & 13 & 13 & 1859 & 0 \\
\hline Bromide & $<0.1$ & $<0.1$ & $<0.1$ & $<0.1$ & 1039 & 0 \\
\hline Zinc & $<0.1$ & $<0.1$ & $<0.1$ & $<0.1$ & $<0.1$ & 0 \\
\hline Phosphate & $<0.1$ & $<0.1$ & $<0.1$ & $<0.1$ & 5 & 0 \\
\hline Chloride & 1912 & 1620 & 1800 & 1250 & 158,518 & 96,566 \\
\hline Sulfate & 3067 & 3394 & 2950 & 3604 & 268 & 885 \\
\hline Bicarbonate & 12.3 & 12.3 & 2.46 & 2.46 & 43 & 332 \\
\hline Nitrate & 0 & 0 & 0 & 0 & 4 & 0 \\
\hline Strontium & 0 & 0 & 0 & 0 & 944 & $<0$ \\
\hline Carbonate & $<0.1$ & $<0.1$ & $<0.1$ & $<0.1$ & $<0.1$ & $<0.1$ \\
\hline TDS (MG/L) & 6605.7 & 7167.7 & 6586.46 & 7762.46 & 258,249 & 157,488 \\
\hline
\end{tabular}

oil for 3 weeks prior to sequential LSWF with the numerous brines.

\section{Systems wettability measurements}

Six diskettes were cut from one core. Three were saturated with formation brine. The water-saturated diskettes were also aged in the same brine for three weeks. The other three were saturated with reservoir oil. They were similarly aged in the same oil for three weeks. Aging was done at temperature and pressure of $90{ }^{\circ} \mathrm{C}$ and 200 psia. Water-saturated diskettes were placed in a glass beaker filled with formation brine. Oil droplets were later placed on the surface of the water-saturated diskettes. After $24 \mathrm{~h}$, water-oil contact angles were measured. They were found to be at around $45^{\circ}$, confirming that the diskettes were water-wet. The oilsaturated diskettes were placed in glass beakers filled with formation brine for more than $24 \mathrm{~h}$. No oil drops appeared on the surface of the diskettes. That confirms that the oilsaturated diskettes reached complete oil wetness.

\section{Core flooding experiments}

Core flooding was designed to assess the potential of water injection under dynamic conditions and in different wettability environments. Flooding experiments were considered to evaluate the effect of dilution and sulfate spiking on the DE. A series of five core flooding experiments were conducted (refer to Table 3). Every single core was flooded with a specific set of brines, sequentially, to eliminate the effect of variation in the rocks' petrophysical properties. An injection rate of $1 \mathrm{cc} / \mathrm{min}$ was used in all core floods. Table 4 presents the order of the injected brines for every core flooding experiment. All effluents were analyzed for $\mathrm{pH}$, resistivity, turbidity, and total dissolved solids (TDS).
Table 3 Basic properties of the core plugs

\begin{tabular}{llll}
\hline Wettability & Sample & Water & Porosity \\
\hline \multirow{3}{*}{ WW } & ID & $\mathrm{k}(\mathrm{Md})$ & $\%$ \\
& 18 & 20.60 & 11.00 \\
& 38 & 10.30 & 11.00 \\
& $24 \mathrm{~S}$ & 11.30 & 13.00 \\
& 2 & 11.60 & 15.00 \\
OW & 8 & 12.20 & 16.00 \\
& 22 & 15.50 & 14.00 \\
& 2 & 10.99 & 12.00 \\
& 5 & 14.05 & 15.00 \\
& $22 \mathrm{~S}$ & 12.00 & 13.00 \\
& 3 & 11.10 & 12.00 \\
\hline
\end{tabular}

Table 4 Sequential order of brine injection

\begin{tabular}{llll}
\hline Sequential & \multicolumn{3}{l}{ Sequential order of brine injection } \\
\cline { 2 - 4 } & First & Second & Third \\
\hline I & SW & SWX 2 SO4 & SWX 6 SO4 \\
II & SW/10 & SW/10 X 2 SO4 & SW/10 X 6 SO4 \\
III & SW/50 & SW/50 X 2 SO4 & SW/50 X 6 SO4 \\
IV & SW & SW/10 & SW/50 \\
V & IW & SW/10 & \\
\hline
\end{tabular}

\section{Results and discussion}

\section{Low-salinity recovery mechanism}

Zekri et al. (2020) identified the dominant recovery mechanisms for low-salinity sequential flooding in intermediate-wet rock; namely rock dissolution and water-in-oil 
emulsion. Results of that work will be used to compare with the performance of sequential brines in oil- and water-wet environments.

\section{Water-wet system}

\section{Effect of sulfate concentration}

The initial core flooding experiments used 18 cores with an initial water saturation of around $15.4 \%$. The cores were flooded with SW first. SW was then spiked with twice and 6-times the sulfate concentration, respectively. Results of the sequential I flooding are presented in Fig. 1.

Sequential I flooding started with SW injection. It yielded a recovery of $78.50 \%$ of the OOIP after the injection of 10.6 pore volumes (PVs). Further water injection showed no improvement in oil recovery as the water cut remained constant. In order to evaluate the effect of sulfate, the injection system was changed to $\mathrm{SWX}_{2} \mathrm{SO}_{4}$ (spiked seawater with twice the sulfate concentration. Injection was continued for up to 23.5 PVs. Spiked seawater yielded an enhancement of $2.2 \%$ in the displacement efficiency, DE. The displacement efficiency defined as follows:

$\mathrm{DE}=\frac{S_{\mathrm{oi}}-S_{o}}{S_{\mathrm{oi}}}$

$S_{\mathrm{oi}}=$ Initial oil saturation @ the start of the flood.

$S_{o}=$ Average oil saturation @ the end of the flood.

After a sequential flooding (with SW and then $\mathrm{SWX}_{2} \mathrm{SO}_{4}$ ) for a total of $27.8 \mathrm{PVs}$, the flooding system was switched to
SWX6 $6 \mathrm{SO}_{4}$ (spiked seawater with 6 times the sulfate concentration). $\mathrm{SWX}_{6 \mathrm{SO}}$ yielded an additional $0.2 \%$ and the overall DE was estimated to be around $80.93 \%$. Table 5 presents brines prior- and post-flooding properties. These results indicated that there is a slight increase in the $\mathrm{pH}$ of the produced $\mathrm{SW}$ as well as the $\mathrm{SWX} 2 \mathrm{SO}_{4}$. Post-flooding water analysis revealed a slight increase in total dissolved solids and turbidity. This indicates that a minor dissolution took place during the flooding process. Alteration of total dissolved solids TDS is most likely due to dissolution. The alterations were, however, minor and non-conclusive. The resistivity measurements of the effluents showed a slight decline. This is attributed to the increase in produced water salinity and confirms the conclusion drawn previously regarding the limited improvement of the DE caused by sulfate-spiked seawater flooding.

\section{Effect of dilution}

To study the effect of dilution on the displacement efficiency, a sequential IV flooding was performed (SW, 10-times diluted SW, and 50-times diluted SW). This flood was carried out using core sample 2 . The results for the sequential flooding are shown in Fig. 2.

These results showed that the dilution of seawater has a significant effect on the DE of oil in a water-wet carbonate formation. The DE from SW flooding was estimated to be around $61.5 \%$ after the injection of 6.9 PVs. Ten-times and 50-times diluted seawater were then utilized. The DE improved by 21.9 and $4.6 \%$, respectively. Total displacement efficiency of sequential IV mounted to around $88 \%$.
Fig. 1 DE of sequential I flooding, water-wet system

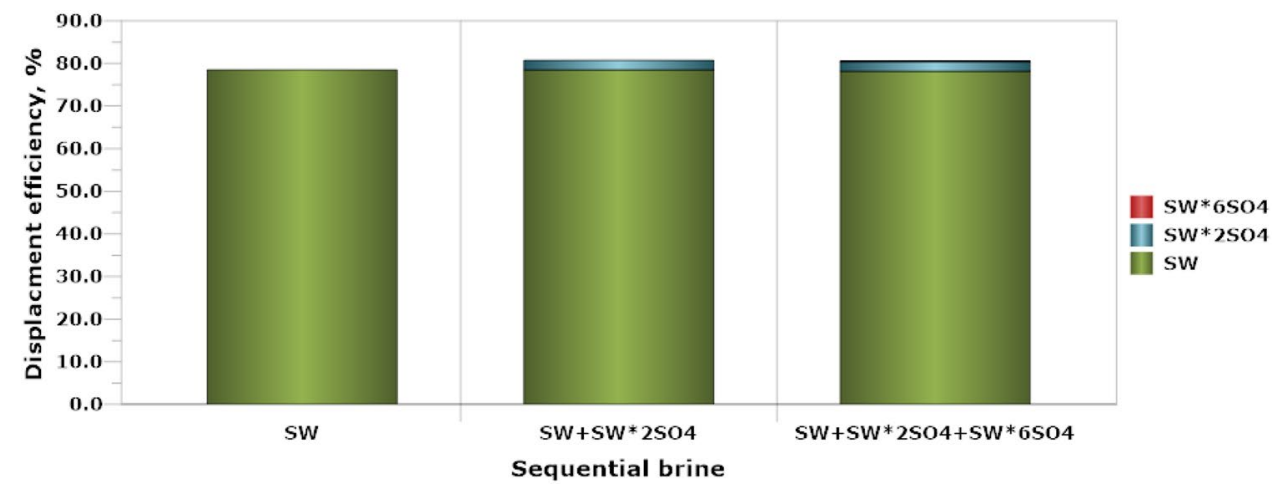

\begin{tabular}{|c|c|c|c|c|c|c|c|}
\hline \multicolumn{2}{|l|}{ Effluent properties } & \multicolumn{2}{|l|}{ SW } & \multicolumn{2}{|c|}{ SW X 2 SO4 } & \multicolumn{2}{|c|}{ SW X $6 \mathrm{SO} 4$} \\
\hline Parameter & Units & Before & After & Before & After & Before & After \\
\hline $\mathrm{pH}$ & $\log (\mathrm{mol} / \mathrm{L})$ & 8.1 & 7.81 & 8.53 & 8.14 & 8.73 & 8.42 \\
\hline Total Dissolved Solids & $\mathrm{mg} / \mathrm{L}$ & 53,611 & 61,462 & 48,731 & 55,984 & 54,290 & 72,840 \\
\hline Resistivity & (Ohm-meter) & 0.174 & 0.169 & 0.177 & 0.176 & 0.215 & 0.212 \\
\hline Turbidity & NTU & 0 & 4 & 0 & 6 & 0 & 7 \\
\hline
\end{tabular}

Table 5 Properties of sequential I brines prior and post flooding, water-wet system 
The improvement of the DE in water-wet environment is attributed to the emulsion mechanism. Water-in-oil emulsion increased substantially in water-wet systems, where oil is located in the middle of larger pores and is surrounded by water. On the other hand, in case of an oil-wet environment, oil spreads on the surface area of the rock and does not trigger emulsion. The results proved that low salinity works effectively in a water-wet carbonate rock environment due to the combined effects of wettability and dissolution. Experimental results of properties of the utilized waters, priorand post-flooding, are presented in Table 6. Data clearly demonstrated that dissolution during low-salinity flooding took place. That has been depicted in an increase of the $\mathrm{pH}$, turbidity, and suspended solids, as well as in a reduction of resistivity of the effluent waters.

\section{Effect of dilution and sulfate concentration}

To study the effect of dilution and sulfate spiking, two sequential experiments (II and III) were performed using water-wet limestone rocks. In sequential II, 10-times diluted seawater and the diluted seawater spiked 2 and 6 times with sulfate were employed. The sequential flood consists of injecting SW/10, followed by SW/10*2SO $\mathrm{SW} / 10 * 6 \mathrm{SO}_{4}$. Figure 3 indicated that sulfate spiking of 10-times diluted SW yielded slight improvement in the DE and the overall DE of this system estimated to be around $76.2 \%$.

In sequential III, 50-times diluted seawater and the diluted seawater spiked 2 and 6 times with sulfate. The sequential flood consists of injecting SW/50, followed
Fig. 2 Displacement efficiency of sequential IV flooding, waterwet system
Table 6 Properties of sequential IV brines prior and post flooding, water-wet system

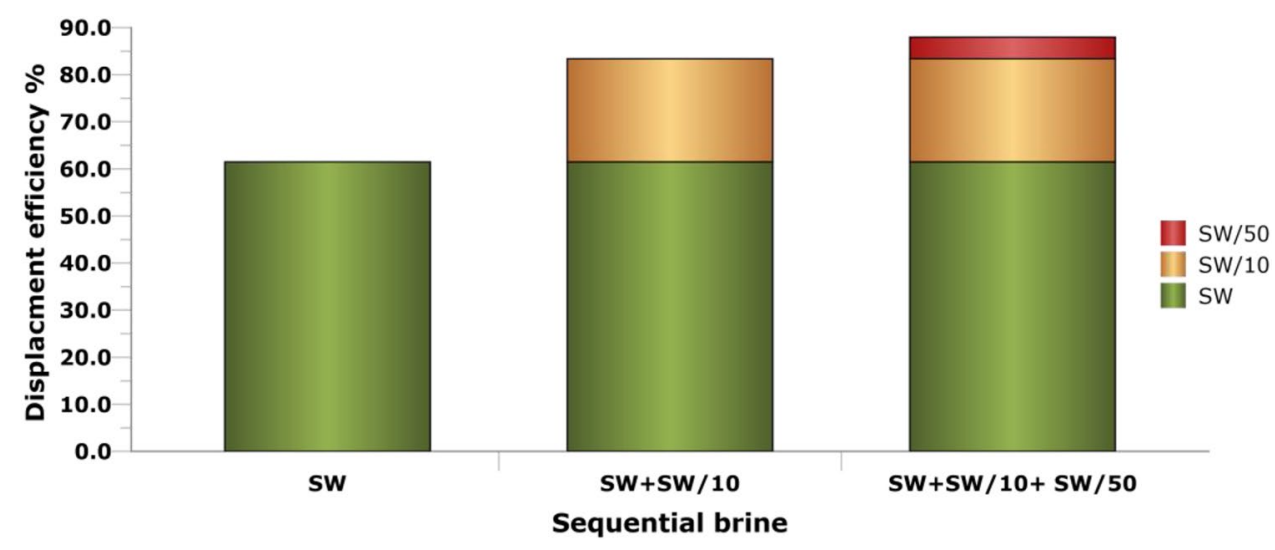

\begin{tabular}{|c|c|c|c|c|c|c|c|}
\hline \multicolumn{2}{|l|}{ Effluent properties } & \multicolumn{2}{|l|}{ SW } & \multicolumn{2}{|l|}{ SW/10 } & \multicolumn{2}{|l|}{$\mathrm{SW} / 50$} \\
\hline Parameter & Units & Before & After & Before & After & Before & After \\
\hline $\mathrm{pH}$ & $\log (\mathrm{mol} / \mathrm{L})$ & 8.1 & 7.74 & 7.89 & 8.46 & 7.84 & 8.17 \\
\hline Total Dissolved Solids & $\mathrm{mg} / \mathrm{L}$ & 53,611 & 64,273 & 5361 & 21,745 & 1072 & 15,600 \\
\hline Resistivity & (Ohm-meter) & 0.174 & 0.172 & 1.531 & 0.174 & 6.271 & 0.21 \\
\hline Turbidity & NTU & 0 & 5 & 0 & 60 & 0 & 35 \\
\hline
\end{tabular}

Fig. 3 Displacement efficiency of sequential II, water-wet system

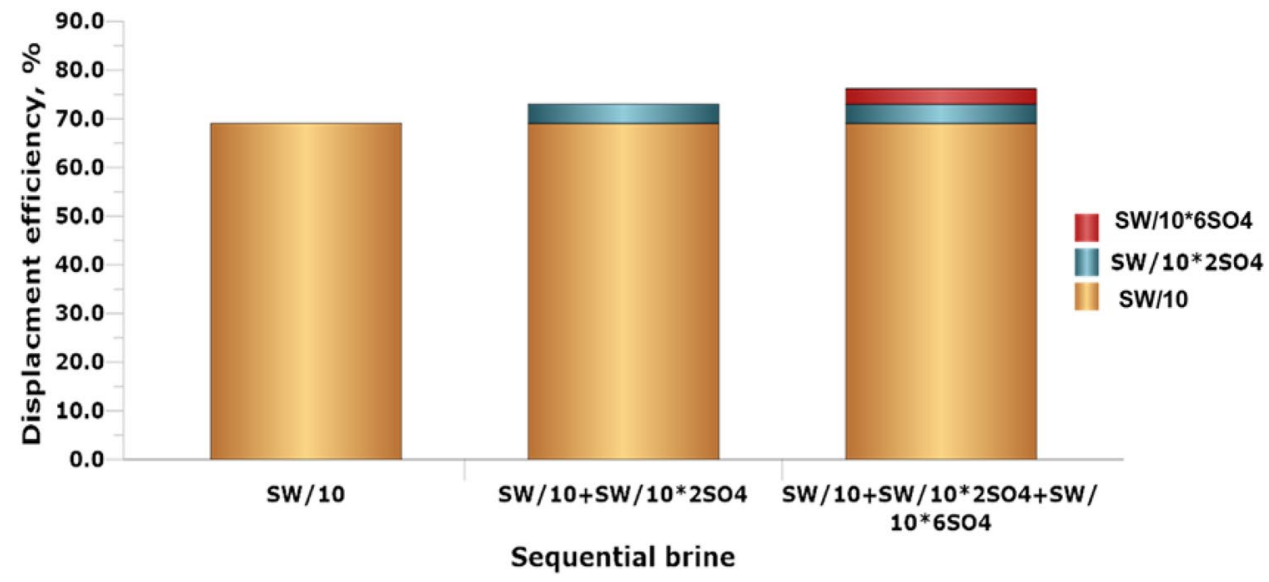

Sequential brine 
by $\mathrm{SW} / 50 * 2 \mathrm{SO}_{4}$, and then $\mathrm{SW} / 50 * 6 \mathrm{SO}_{4}$. Experimental results, as depicted in Fig. 4, indicated that spiking of the 50-times diluted SW yielded insignificant improvement in the DE. Spiked seawater with twice and 6-times the concentration of sulfate added 0.5 and $0.4 \%$ to the $\mathrm{DE}$, respectively. Results indicated that in low salinity environment, sulfate spiking did not play a major role in the improvement of the recovery mechanism.

Tables 7 and 8 present the brines properties for sequential II and sequential III, prior- and post-flooding. Data clearly demonstrated that dissolution had taken place. This is demonstrated by the increase of the $\mathrm{pH}$, turbidity, suspended solids, hardness, and reduction of resistivity of the effluent waters.

Fig. 4 Displacement efficiency of sequential III, water-wet system

Table 7 Properties of sequential II brines prior and post flooding, water-wet system

Table 8 Properties of sequential III brines prior and post flooding, water-wet system

\section{High salinity-low salinity flooding}

In sequential $\mathrm{V}$, using core number 8 , the injected water (high salinity $\approx 260,000 \mathrm{ppm}$ ) and a 10 -times diluted seawater (low salinity $\approx 7,000 \mathrm{ppm}$ ) were used. To simulate the reservoir (under study) present condition, flooding was initiated with the injected water. Figure 5 presents the displacement efficiency of sequential $\mathrm{V}$ flooding. Results revealed that the injection of 10-times diluted seawater added a mere $0.37 \%$ to the DE. Overall displacement efficiency of this sequential was found at around $54.2 \%$ with an additional injection of $15.3 \mathrm{PVs}$.

To assess the dissolution phenomena prior- and postflooding brines' properties were measured (see Table 9). The presented data confirm that dissolution took place during the low-salinity injection phase. A significant increase in the $\mathrm{pH}$, TDS, and turbidity was observed during post-flooding. A

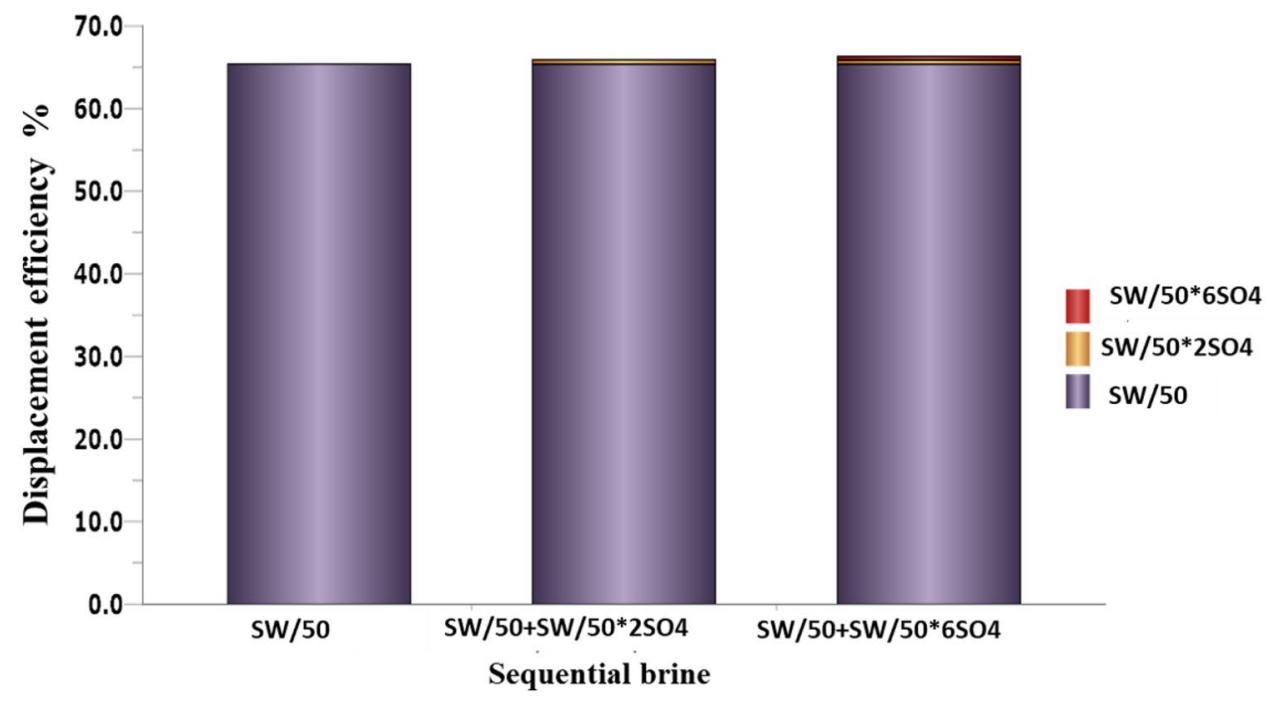

\begin{tabular}{|c|c|c|c|c|c|c|c|}
\hline \multicolumn{2}{|l|}{ Effluent properties } & \multicolumn{2}{|l|}{$\mathrm{SW} / 10$} & \multicolumn{2}{|c|}{$\mathrm{SW} / 10 \times 2 \mathrm{SO} 4$} & \multicolumn{2}{|c|}{ SW/10 X $6 \mathrm{SO} 4$} \\
\hline Parameter & Units & Before & After & Before & After & Before & After \\
\hline $\mathrm{pH}$ & $\log (\mathrm{mol} / \mathrm{L})$ & 7.89 & 8.31 & 8.29 & 8.51 & 8.45 & 8.89 \\
\hline Total Dissolved Solids & $\mathrm{mg} / \mathrm{L}$ & 5361 & 23,789 & 6606 & 30,164 & 7068 & 34,847 \\
\hline Resistivity & (Ohm-meter) & 1.531 & 0.931 & 0.212 & 0.215 & 0.258 & 0.249 \\
\hline Turbidity & NTU & 0 & 62 & 0 & 70 & 0 & 44 \\
\hline
\end{tabular}

\begin{tabular}{|c|c|c|c|c|c|c|c|}
\hline \multicolumn{2}{|l|}{ Effluent properties } & \multicolumn{2}{|l|}{$\mathrm{SW} / 50$} & \multicolumn{2}{|c|}{$\mathrm{SW} / 50 \times 2 \mathrm{SO} 4$} & \multicolumn{2}{|c|}{ SW/50 X 6 SO4 } \\
\hline Parameter & Units & Before & After & Before & After & Before & After \\
\hline $\mathrm{pH}$ & $\log (\mathrm{mol} / \mathrm{L})$ & 7.84 & 7.96 & 8.06 & 8.29 & 8.4 & 8.73 \\
\hline Total Dissolved Solids & $\mathrm{mg} / \mathrm{L}$ & 1072 & 22,160 & 6586 & 31,094 & 6663 & 36,231 \\
\hline Resistivity & (Ohm-meter) & 6.271 & 1.821 & 0.231 & 0.255 & 0.28 & 0.268 \\
\hline Turbidity & NTU & 0 & 62 & 0 & 43 & 0 & 31 \\
\hline
\end{tabular}


Fig. 5 Displacement efficiency of sequential V flooding, waterwet system

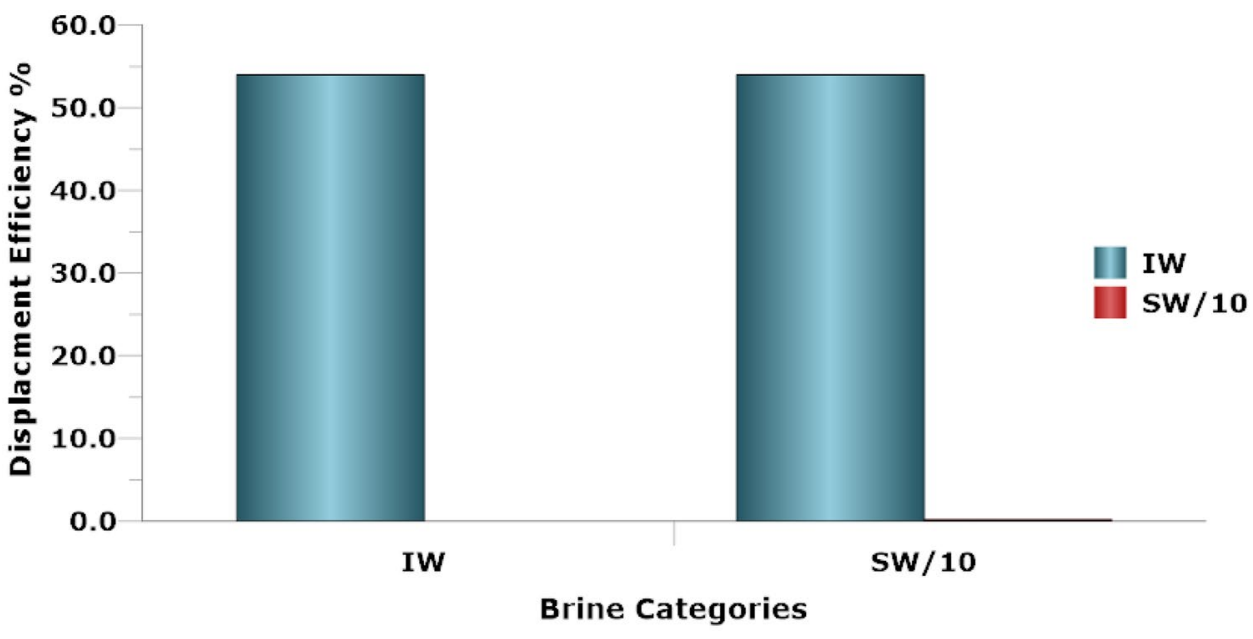

Table 9 Properties of sequential V brines prior and post flooding, water-wet system

\begin{tabular}{|c|c|c|c|c|c|}
\hline \multicolumn{2}{|c|}{ Effluent properties } & \multicolumn{2}{|l|}{ IW } & \multicolumn{2}{|l|}{ SW/10 } \\
\hline Parameter & Units & Before & After & Before & After \\
\hline $\mathrm{pH}$ & $\log (\mathrm{mol} / \mathrm{L})$ & 7.73 & 7.44 & 7.89 & 8.377 \\
\hline $\begin{array}{l}\text { Total Dissolved } \\
\text { Solids }\end{array}$ & $\mathrm{mg} / \mathrm{L}$ & 258,249 & 188,544 & 5361 & 36,687 \\
\hline Resistivity & (Ohm-meter) & 0.062 & 0.061 & 1.531 & 0.512 \\
\hline Turbidity & NTU & 6 & 13 & 0 & 62 \\
\hline
\end{tabular}

$66 \%$ reduction in the resistivity of produced water confirms that the dissolution mechanism was dominant during the low-salinity injection phase. No dissolution, however, was detected during the high-salinity flooding phase. The $\mathrm{pH}$ and TDS decreased while resistivity remained unchanged.

\section{Oil-wet system}

Five core samples were saturated with fresh water and then flooded with reservoir oil until a water cut of zero was achieved. Material balance was used to estimate irreducible water saturations, $S_{\mathrm{wi}}$. The core samples were then aged in oil for a period of 2 weeks. The samples were subsequently flooded with oil prior to sequential water flooding.

\section{Effect of sulfate concentration}

Core number $22 \mathrm{~S}$ was injected with seawater first. The flood was followed by seawater with twice and 6-times the sulfate concentration. The brine injection was continued until oil ceased to flow. Figure 6 displays the displacement efficiency during the different stages of the sequential floods. Results indicated that the spiking of seawater with sulfate had no significant effect on the displacement efficiency. No change in the water endpoint relative permeability was observed. This indicates that no change in wettability took place. The post- and prior-flooding water properties are presented in Table 10. Results indicated that there was no significant change in the resistivity of the produced water. However, the acidity and $\mathrm{pH}$ were slightly reduced in all produced waters, especially in the ones that have been spiked with sulfate. As such, no conclusive evidence supports the possibility of rock dissolution in the oil-oil-wet environment.
Fig. 6 Displacement efficiency of sequential seawater and spiked SW flooding, oil-wet system

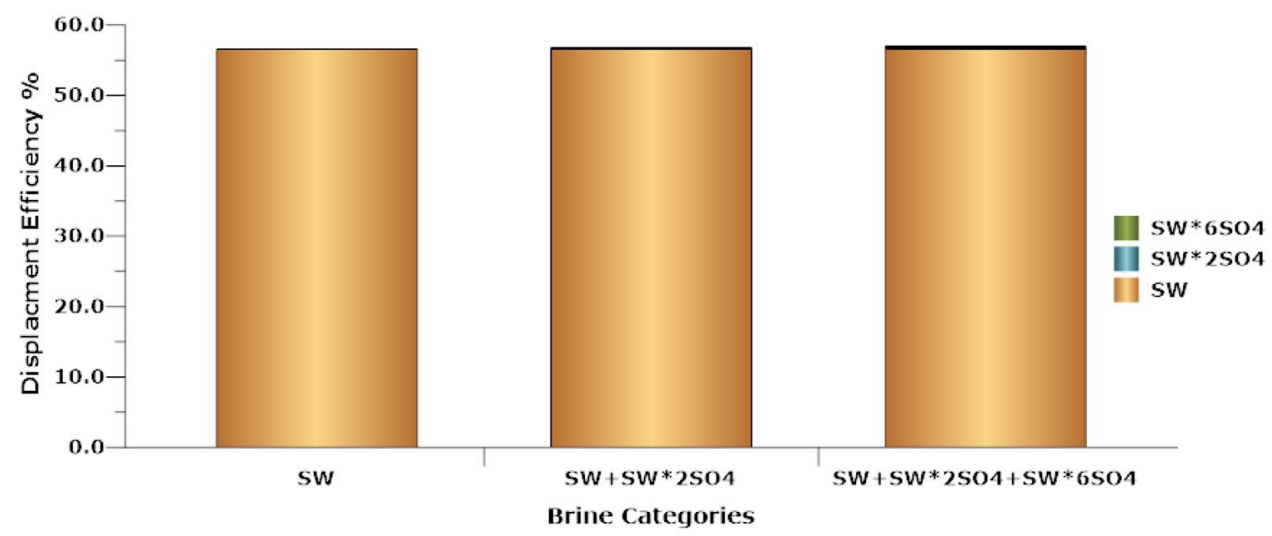


Table 10 Properties of SW flooding and spiked SW prior and post flooding, oil-wet system

\begin{tabular}{|c|c|c|c|c|c|c|c|}
\hline \multicolumn{2}{|l|}{ Effluent properties } & \multicolumn{2}{|l|}{ SW } & \multicolumn{2}{|c|}{ SWX $2 \mathrm{SO} 4$} & \multicolumn{2}{|c|}{ SW X $6 \mathrm{SO} 4$} \\
\hline Parameter & Units & Before & After & Before & After & Before & After \\
\hline $\mathrm{pH}$ & $\log (\mathrm{mol} / \mathrm{L})$ & 8.1 & 7.68 & 8.53 & 8.52 & 8.73 & 8.3 \\
\hline Total Dissolved Solids & $\mathrm{mg} / \mathrm{L}$ & 53,611 & 59,517 & 48,731 & 62,364 & 54,290 & 69,204 \\
\hline Resistivity & (Ohm-meter) & 0.174 & 0.161 & 0.177 & 0.171 & 0.215 & 0.206 \\
\hline Turbidity & NTU & 0 & 5 & 0 & 8 & 0 & 8 \\
\hline
\end{tabular}

\section{Effect of dilution}

To study the effect of dilution on the displacement efficiency in an oil-wet environment, sequential IV flooding was performed. The flooding sequence involved seawater, 10-times, and 50-times diluted seawater. Results indicated that dilution of seawater has a negative impact on the displacement efficiency in an oil-wet environment (see Fig. 7). Seawater alone produced better results thanks to dissolution and emulsion. These mechanisms were enhanced by a higher interfacial activity, as reported by Zekri et al. (2020). Researchers agree that ionic exchange phenomenon is the dominant production mechanism in oil-wet systems, where calcium ions are detached from the rock surface area carrying oil droplets and replacing them with magnesium ions. The sulfate ions are absorbed first on the limestone surface, neutralizing the charge of the rock surface. It is, therefore, expected to observe an increase in $\mathrm{Ca}^{2+}$ and a decrease in $\mathrm{Mg}^{2+}$ and $\mathrm{SO}_{4}{ }^{2-}$ ions in the produced water during low-salinity flooding for the ionic exchange mechanism to take place. This did not manifest in the flood, as shown in the data presented in Figs. 7 (a, b, and c). This confirms that ionic exchange and wettability alteration did not take place.

\section{Effect of dilution and sulfate concentration}

Sequential II and III of the LSWF experiments in oil-wet environment consisted of using two diluted waters (10-times and 50-times) spiked with twice and 6-times the sulfate concentration. Cores number 2 and 6 were used for the 10-times and 50-times diluted seawater experiments, respectively. Figure 8 illustrates the DE achieved with seawater, 10-times diluted seawater, 50-times diluted seawater, and the injected water in the field under study. The optimum salinity for the oil-wet system was found to be at 7,000 ppm and further reduction in salinity did not improve the system DE.

Sulfate spiking was also tested in seawater flooding of oil-wet systems. Experimental results (as shown in Fig. 9) indicate that spiking of 10-times diluted seawater had a slight improvement in the DE, with an increment of $1.8 \%$. The overall DE increased to $52.7 \%$. Experimental results presented in Fig. 10 indicated that spiking of the 50-times diluted seawater had no significant improvement in the DE.
A slight rock dissolution, as observed from the endpoints of the effective permeability curves, could have taken place.

A slight reduction in the $\mathrm{pH}$ of the spiked and non-spiked 10-times diluted seawater was observed. An insignificant increase in the $\mathrm{pH}$, however, was noted for the 50-times diluted seawater and its spiked waters (see Tables 11 and 12). The sulfate-spiked brines acted as neutral waters as no meaningful change in DE was observed for the oil-wet limestone rock.

\section{High salinity-low salinity flooding}

The final sequential flooding of brines is category V. Field water flooding followed by a 10-times diluted seawater was performed. This experiment was carried out using core number 3 . The performance of sequential $\mathrm{V}$ is presented in Fig. 11 and brines' properties prior- and post-flooding are displayed in Table 13. The high salinity (case study field water) water flooding resulted in a DE of $50.6 \%$. Subsequent injection of 10-times diluted seawater did not improve the DE of the system. As presented in Table 13, there was no significant change in the $\mathrm{pH}$ of prior- and post-flooding brines as the brines acted as neutral waters. The resistivity of the field water did not change, that of the 10-times diluted seawater, however, declined. Data also indicated that the TDS displayed a significant reduction during field waterflood and an increase during the 10-times diluted seawater flood. The results were attributed to the possibility of ionic precipitation during field water injection followed by dissolution into the low-salinity brine during 10-times diluted sweater flooding. No additional oil recovery was observed during the 10-times diluted seawater flood. This could be explained by the fact that as 10-times diluted seawater fills in the porous medium, mixing with high-salinity field water took place. Such mixing resulted in a high overall salinity that hindered the emulsion mechanism.

\section{Effect of wettability on the performance of low salinity flooding}

Results clearly indicate that the reservoir wettability has a significant effect on the displacement efficiency of lowsalinity waterflooding. Surprisingly, diluted seawater in a water-wet system displayed higher performance compared 
Fig. 7 a Ionic concentration of injection and production brines b Ionic concentration of injection and production brines $\mathbf{c}$ Ionic concentration of injection and production brines

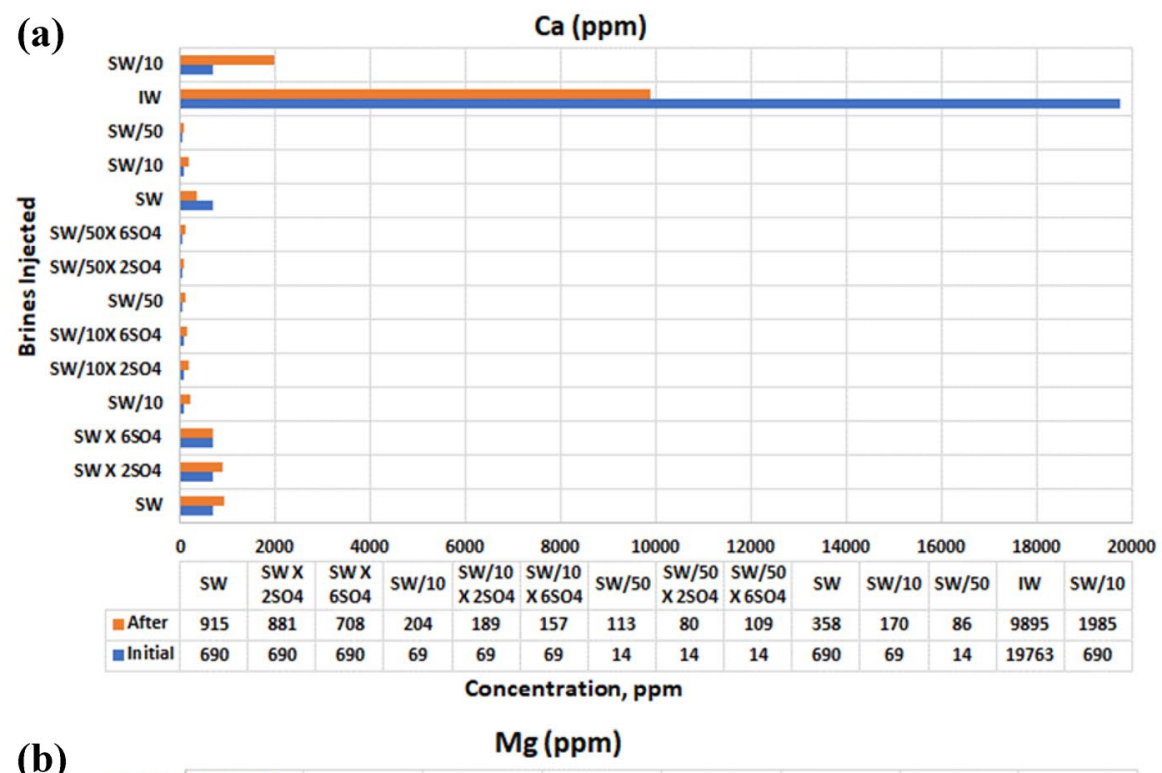

(b)

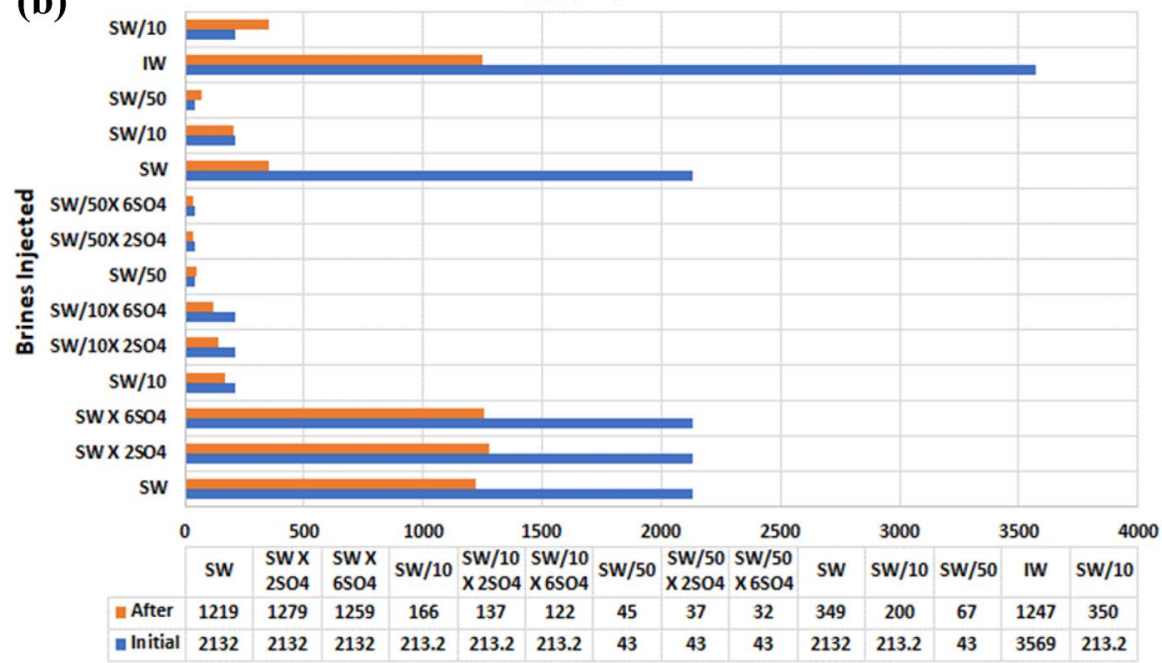

Concentration, ppm

(c)

SO4 (ppm)

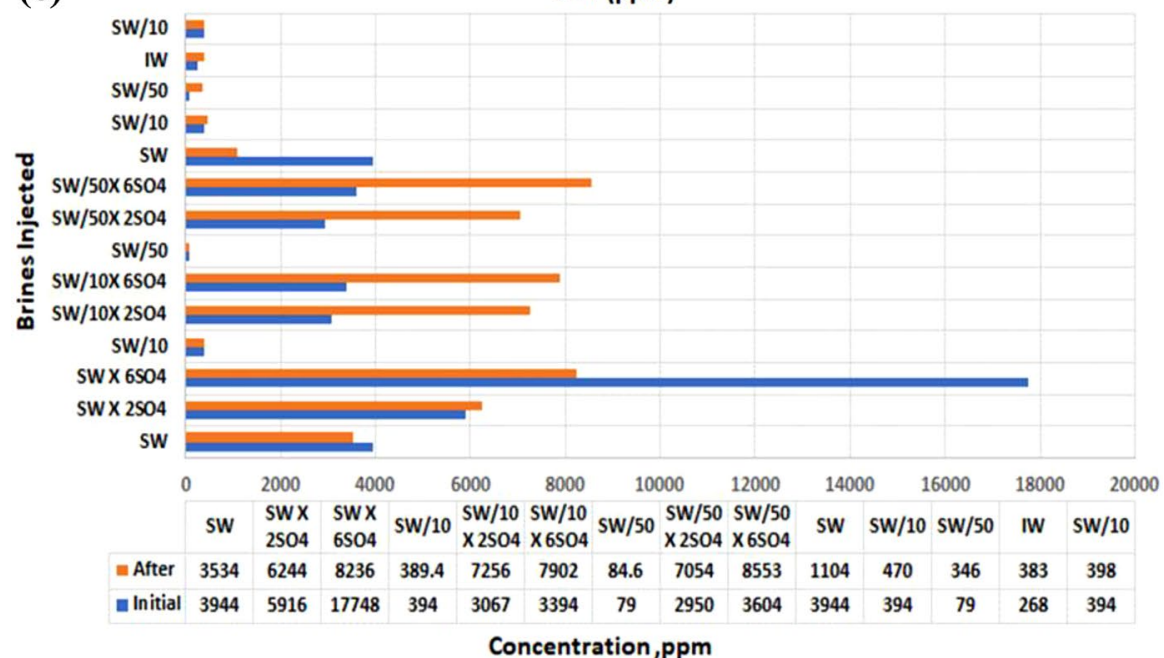


Fig. 8 Displacement efficiency of seawater as function of dilution

Fig. 9 DE of sequential sea water diluted 10 times and spiked, oil-wet system

Fig. 10 DE of sequential SW diluted 50 times and spiked, oil-wet system

Table 11 Properties of SW/10 spiked prior and post flooding, oil-wet system
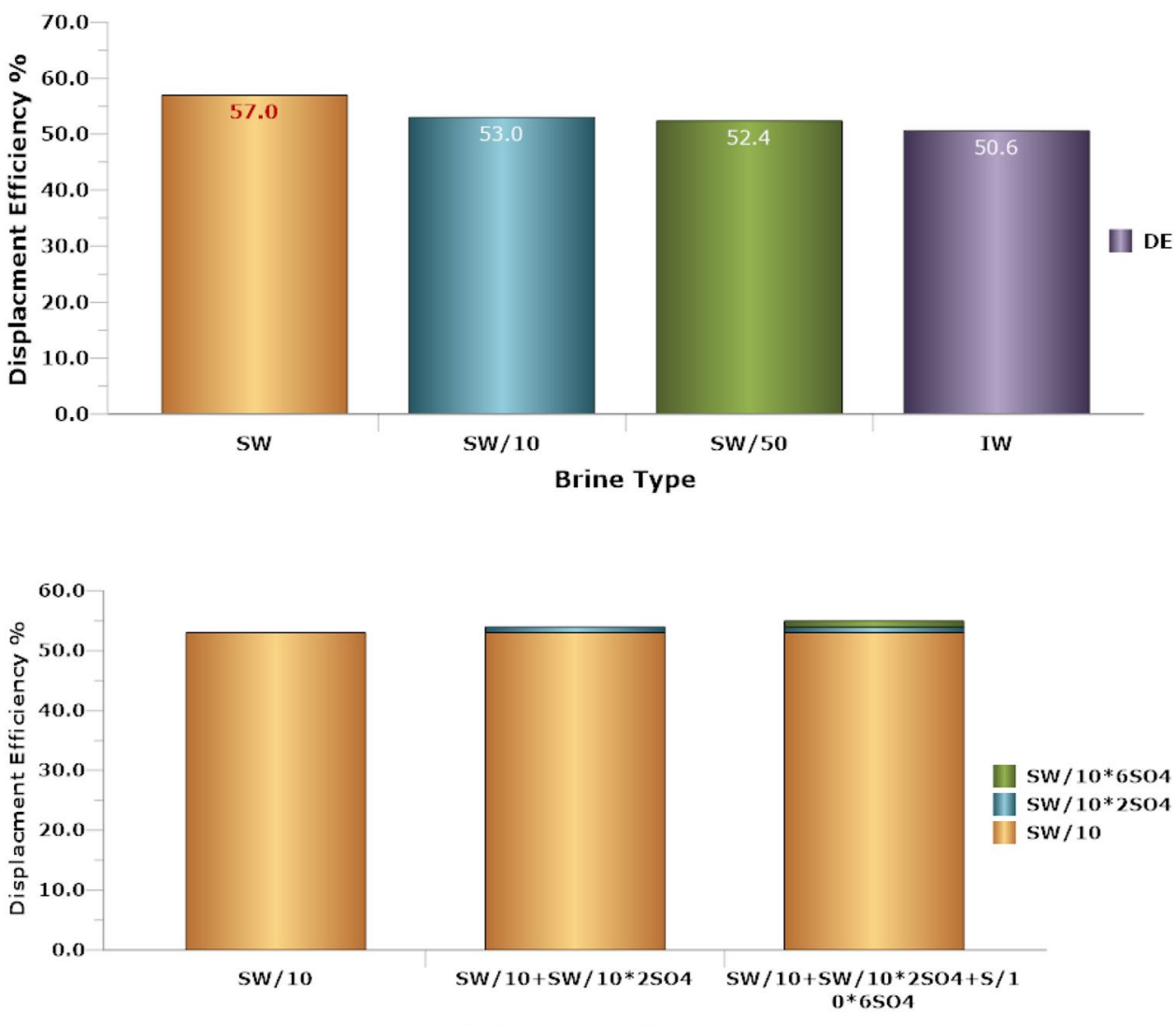

Brine Categories

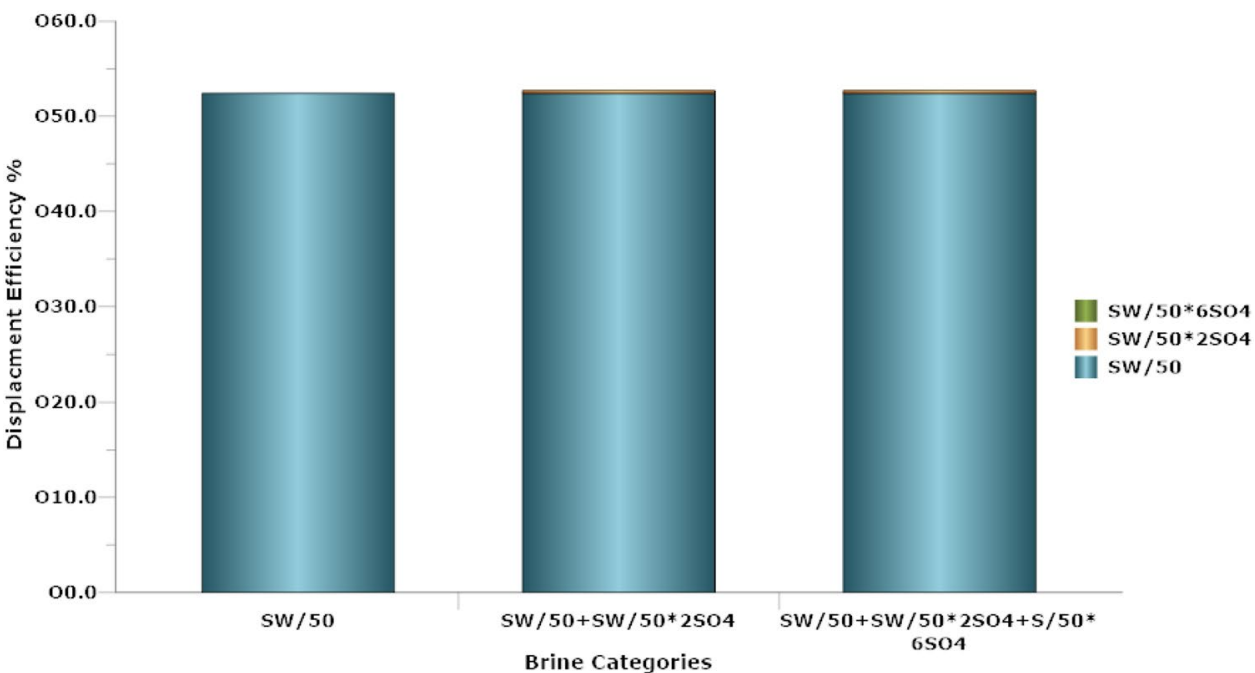

\begin{tabular}{|c|c|c|c|c|c|c|c|}
\hline \multicolumn{2}{|l|}{ Effluent properties } & \multicolumn{2}{|l|}{ SW/10 } & \multicolumn{2}{|c|}{$\mathrm{SW} / 10 \times 2 \mathrm{SO} 4$} & \multicolumn{2}{|c|}{ SW/10 X $6 \mathrm{SO} 4$} \\
\hline Parameter & Units & Before & After & Before & After & Before & After \\
\hline $\mathrm{pH}$ & $\log (\mathrm{mol} / \mathrm{L})$ & 7.89 & 7.88 & 8.29 & 7.91 & 8.45 & 8.04 \\
\hline Total Dissolved Solids & $\mathrm{mg} / \mathrm{L}$ & 5361 & 35,632 & 6606 & 46,472 & 7068 & 38,940 \\
\hline Resistivity & (Ohm-meter) & 1.531 & 1.023 & 0.212 & 0.209 & 0.258 & 0.243 \\
\hline Turbidity & NTU & 0 & 54 & 0 & 60 & 0 & 37 \\
\hline
\end{tabular}


Table 12 Properties of SW/50 spiked prior and post flooding, oil-wet system

\begin{tabular}{|c|c|c|c|c|c|c|c|}
\hline \multicolumn{2}{|l|}{ Effluent properties } & \multicolumn{2}{|l|}{$\mathrm{SW} / 50$} & \multicolumn{2}{|c|}{$\mathrm{SW} / 50 \times 2 \mathrm{SO} 4$} & \multicolumn{2}{|c|}{ SW/50 X $6 \mathrm{SO} 4$} \\
\hline Parameter & Units & Before & After & Before & After & Before & After \\
\hline $\mathrm{pH}$ & $\log (\mathrm{mol} / \mathrm{L})$ & 7.84 & 8.12 & 8.06 & 8.16 & 8.4 & 8.44 \\
\hline Total Dissolved Solids & $\mathrm{mg} / \mathrm{L}$ & 1072 & 27,391 & 6586 & 28,810 & 6663 & 37,463 \\
\hline Resistivity & (Ohm-meter) & 6.271 & 2.78 & 0.231 & 0.23 & 0.28 & 0.273 \\
\hline Turbidity & NTU & 0 & 21 & 0 & 37 & 0 & 24 \\
\hline
\end{tabular}

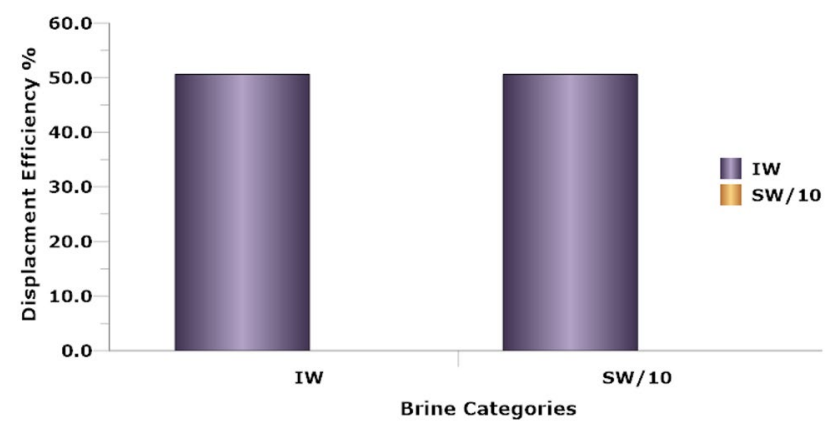

Fig. 11 DE of sequential IW and SW diluted 10, oil-wet system

Table 13 Properties of IW and SW/10 prior and post flooding, oilwell system

\begin{tabular}{|c|c|c|c|c|c|}
\hline \multicolumn{2}{|c|}{ Effluent properties } & \multicolumn{2}{|l|}{ IW } & \multicolumn{2}{|l|}{$\mathrm{SW} / 10$} \\
\hline Parameter & Units & Before & After & Before & After \\
\hline $\mathrm{pH}$ & $\log (\mathrm{mol} / \mathrm{L})$ & 7.73 & 7.60 & 7.89 & 7.99 \\
\hline $\begin{array}{l}\text { Total Dissolved } \\
\text { Solids }\end{array}$ & $\mathrm{mg} / \mathrm{L}$ & 258,249 & 176,378 & 5361 & 22,747 \\
\hline Resistivity & (Ohm-meter) & 0.062 & 0.063 & 1.531 & 0.274 \\
\hline Turbidity & NTU & 6 & 10 & 0 & 49 \\
\hline
\end{tabular}

to oil-wet and intermediate-wettability systems. Researchers agree that low-salinity flooding works better in carbonate formations (oil- and intermediate-wet) mainly through ionic exchange in the absence of clays. Low-salinity waterflooding is more efficient in water-wet sandstones in the presence of clays. In such systems, emulsion and dissolutions play a major role in the improvement of the displacement efficiency since oil droplets occupy the larger pores and move to the middle of the pore space. Based on previous analysis, low-salinity 10-times diluted seawater flooding $(\leq 5,000 \mathrm{ppm})$ is more efficient in a water-wet environment. Seawater, however, $(\approx 50,000 \mathrm{ppm})$ produced the highest DE in oil-wet and intermediate-wettability systems. Figure 12 and Table 14 present the displacement efficiencies for seawater, 10-times and 50-times diluted seawater as well as injected field water.

Endpoint water relative permeabilities were measured and presented in Table 15, for different wettability systems using diluted seawater and field water. Figure 13 presents the results of water relative permeability at residual oil saturation for the studied cases. Craig's rule of thumb was used to qualify the system wettability. The rule stated that relative permeability to water at maximum water saturation is generally less than $30 \%$ for a water-wet system and greater than 50\% for an oil-wet system (Craig, 1971). Based on that, for the oil-wet system, low-salinity water (10-times and 50-times dilution) shifted the system wettability to water-wet. Seawater, however, modified the rock wetness to intermediate most likely through dissolution.

As shown in Fig. 13 and Table 15, results indicated that dilution of seawater changed the rock wettability from intermediate- to oil-wet and that explains why DE was low for both cases.
Fig. 12 Displacement efficiency of SW, diluted seawater, for different wettability systems

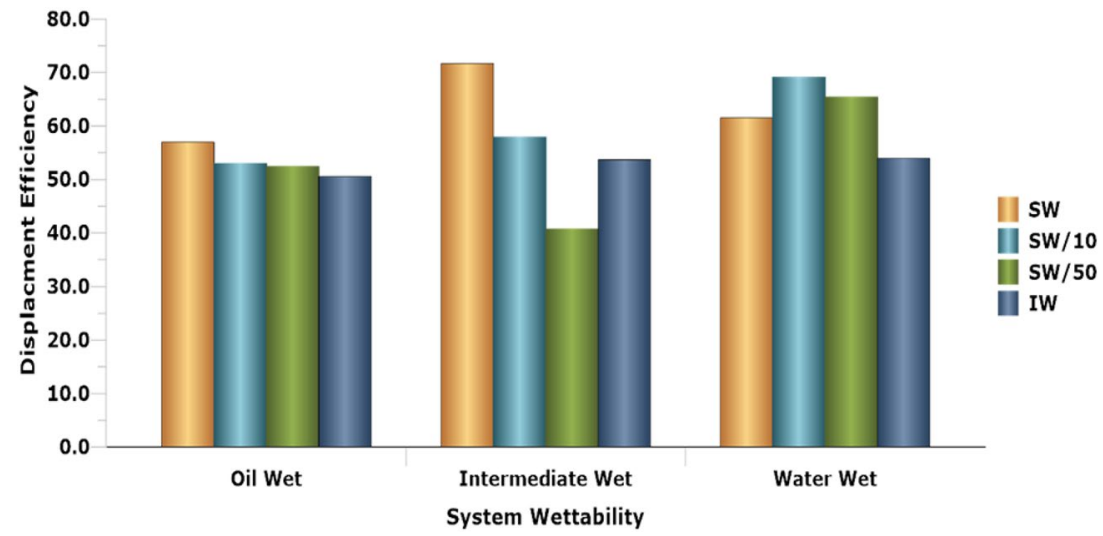

مدينة الملك عبدالعزيز

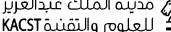


Table 14 DE of different diluted and IW brines for oil-wet and waterwet systems

\begin{tabular}{llll}
\hline & Oil wet & Intermediate wet & Water wet \\
\hline SW & 57 & 71.7 & 61.5 \\
SW/10 & 53 & 57.9 & 69.1 \\
SW/50 & 52.4 & 40.8 & 65.4 \\
IW & 50.6 & 53.7 & 54 \\
\hline
\end{tabular}

Table 15 Water-endpoint relative permeability for the different wettability systems

\begin{tabular}{llll}
\hline Brine & Oil wet & Intermediate wet & Water wet \\
\hline SW & 0.31 & 0.39 & 0.41 \\
SW/10 & 0.14 & 0.54 & 0.37 \\
SW/50 & 0.18 & 0.65 & 0.16 \\
IW & 0.26 & 0.46 & 0.43 \\
\hline
\end{tabular}

The displacement efficiency of the sequential systems used in this study is affected by the system wettability as displayed in Fig. 14. The sequential IV (seawater/10-times/50-times diluted seawater) is the optimum sequential system for oil- and water-wet systems. Sequential III (50-times diluted seawater, 50 -times diluted seawater with twice the sulfate concentration, 50-times diluted seawater with 6 times the sulfate concentration) is the optimum sequential for intermediate wettability. In addition, spiking diluted seawater with sulfate did not show an improvement in the displacement efficiency of both oil- and water-wet environments. Overall, the optimum system for sequential injection is sequential IV in water-wet environment. Such system yielded a DE of $88 \%$ (refer to Fig. 14 and Table 16).

The displacement efficiency of high-salinity seawater followed by diluted seawater injection in water-wet systems is higher than what was reported in other enhanced oil recovery processes, such as chemical and miscible flooding. Experimental results indicated that sulfate spiking has no significant effect on the performance of the process when initiating sequential flooding with one of the following low-salinity waters (salinity $\approx 50,000,5,000$, or $1,000 \mathrm{ppm}$ ) followed with spiked seawater with twice and six-times the sulfate concentration.
Fig. 13 Endpoint relative permeability for the different wettability systems
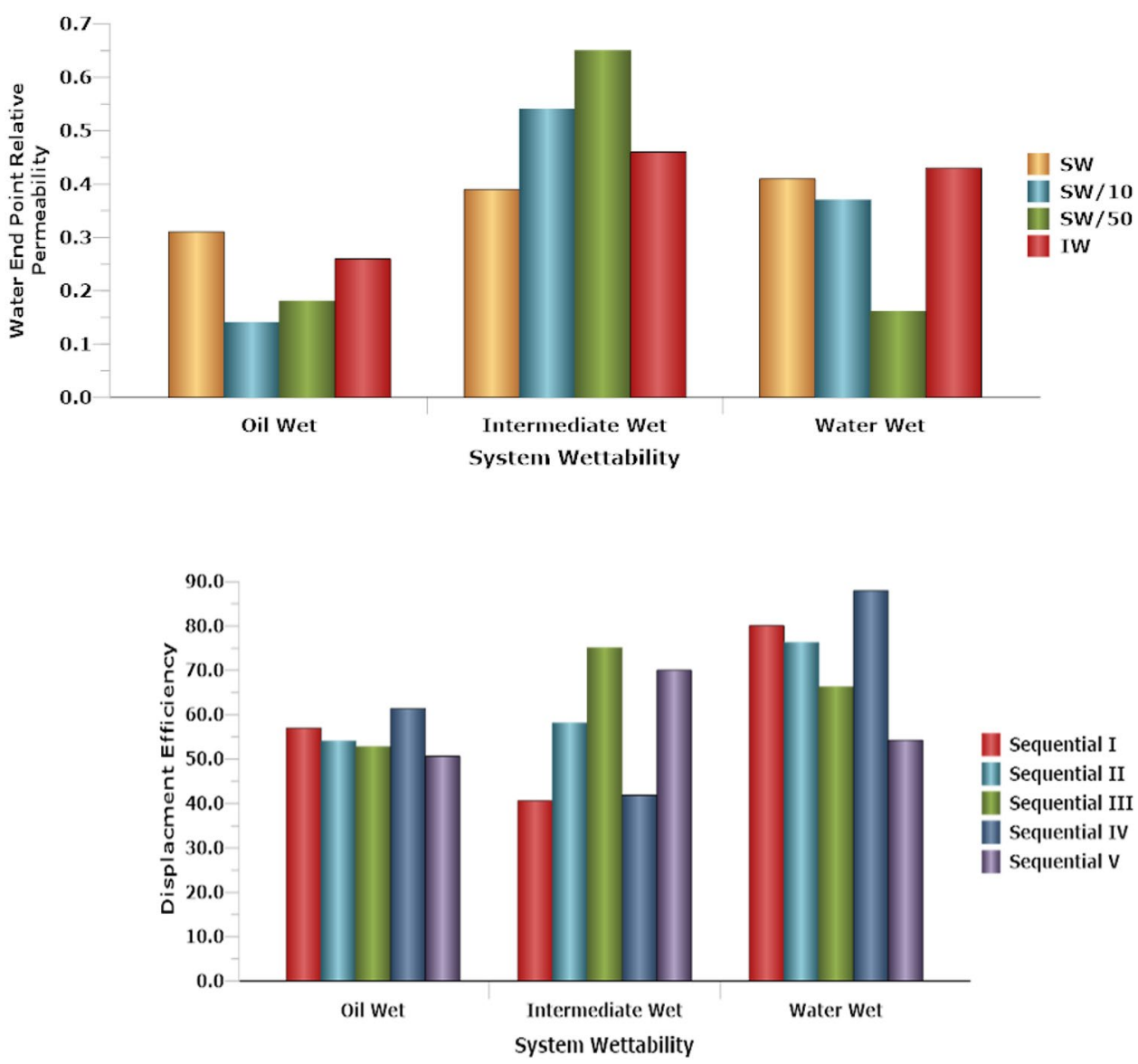

Fig. 14 Displacement efficiency for sequential flooding as a function of system wettability 
Table 16 DE of different sequential brine flooding for oil-wet, intermediate-wet and water-wet systems

\begin{tabular}{llll}
\hline & Oil wet & Intermediate wet & Water wet \\
\hline Sequential I & 57 & 40.7 & 80.09 \\
Sequential II & 54 & 58.12 & 76.2 \\
Sequential III & 52.7 & 75.09 & 66.3 \\
Sequential IV & 61.4 & 41.82 & 88 \\
Sequential V & 50.6 & 70 & 54.2 \\
\hline
\end{tabular}

\section{Conclusions}

Based on this study's experimental results, it can be concluded that the performance of low-salinity flooding is a function of both recovery mechanism and rock wettability. Under the studied conditions, the optimum water salinity was estimated to be around 50,000 ppm for oiland intermediate-wettability environment and 5,000 ppm for water-wet system. Results also indicated that sulfate spiking of low-salinity waters had no significant impact on the recovery efficiency. In a water-wet environment, sequential flooding IV (seawater/10-times/50-times diluted seawater) is the optimum displacement mechanism among the studied five sequential schemes; it yielded the highest displacement efficiency of $88 \%$.

Acknowledgements The authors would like to acknowledge the ADCO Oil Co., Khalifa University, UAEU Research Affairs, and National Water and Energy Center (project no. 21R011) for their financial support. Special thanks go for Engineers Essa Lwisa and Jassim Abubaker Ponnambathayil for conducting the laboratory work part covering contact angle and IFT measurements used in this study.

Funding This research was funded by Abu Dhabi Company for Onshore Oil Operations (ADCO). Under the project no. 21R011.

\section{Declarations}

Conflict of interests The authors declare that they have no competing interests.

Data availability The data supporting the conclusions of this paper are included within the paper. Any queries regarding these data may be directed to the corresponding author.

Consent for publication Authors have agreed to submit it in its current form for publication in the journal.

Open Access This article is licensed under a Creative Commons Attribution 4.0 International License, which permits use, sharing, adaptation, distribution and reproduction in any medium or format, as long as you give appropriate credit to the original author(s) and the source, provide a link to the Creative Commons licence, and indicate if changes were made. The images or other third party material in this article are included in the article's Creative Commons licence, unless indicated otherwise in a credit line to the material. If material is not included in the article's Creative Commons licence and your intended use is not permitted by statutory regulation or exceeds the permitted use, you will need to obtain permission directly from the copyright holder. To view a copy of this licence, visit http://creativecommons.org/licenses/by/4.0/.

\section{References}

Agbalaka CC, Dandekar AY, Patil SL, Khataniar S, Hemsath, J (2008) The effect of wettability on oil recovery: a review. In: SPE Asia pacific oil and gas conference and exhibition. Society of petroleum engineers. https://doi.org/10.2118/114496-MS.

Alagic E, Spildo K, Skauge A, Solbakken J (2011) Effect of crude oil ageing on low salinity and low salinity surfactant flooding. J Petrol Sci Eng 78(2):220-227. https://doi.org/10.1016/j.petrol. 211.06.021

Al-Shalabi EW, Sepehrnoori K, Pope G, Mohanty, K (2014) A fundamental model for predicting oil recovery due to low salinity water injection in carbonate rocks. In: SPE energy resources conference, Society of petroleum engineers. https://doi.org/10. 2118/169911-MS.

Chandrasekhar, S. (2013). Wettability alteration with brine composition in high temperature carbonate reservoirs. Society of petroleum engineers. Paper 166280, ATCE, New Orleans, Louisiana. https://doi.org/10.2118/166280-MS.

Chandrashegaran, P (2015) Low Salinity Water Injection for EOR. In: SPE Nigeria annual international conference and exhibition, Society of petroleum engineers, https://doi.org/10.2118/ 178414-MS.

DM Clementz (1982) Alteration of rock properties by adsorption of petroleum heavy ends: implications for enhanced oil recovery. In: SPE enhanced oil recovery symposium, Society of petroleum engineers https://doi.org/10.2118/10683-MS

Craig, F.F. (1971). The reservoir engineering aspects of waterflooding. HL Doherty Memorial Fund of AIME New York. 3, 127 134. ISBN: 978-0-89520-202-4.

Gomari KR, Hamouda AA (2006) Effect of fatty acids, water composition and $\mathrm{pH}$ on the wettability alteration of calcite surface. J Petrol Sci Eng 50(2):140-150. https://doi.org/10.1016/j.petro. 2005.10.007

Katende A, Sagala F (2019) A critical review of low salinity water flooding: mechanism, laboratory and field application. Journal Molecular Liquids 278:627-649. https://doi.org/10.1016/j.molliq.2019.01.037

Khilar KC, Fogler HS (1983) Water sensitivity of sandstones. Soc Petrol Eng J 23(01):55-64. https://doi.org/10.2118/10103-PA

Mahani H, Keya AL, Berg S, Bartels WB, Nasralla R, Rossen WR (2015) Insights into the mechanism of wettability alteration by low-salinity flooding (LSF) in carbonates. Energy Fuels 29(3):1352-1367. https://doi.org/10.1021/ef5023847

Morrow N, Buckley J (2011) Improved oil recovery by low salinity waterflooding. J Petrol Technol 63(05):106-112. https://doi.org/ 10.2118/129421-JPT

Mungan N (1965) Certain wettability effects in laboratory waterfloods. J Petrol Technol. https://doi.org/10.2118/1203-PA

Prieve DC, Roman R (1987) Diffusiophoresis of a rigid sphere through a viscous electrolyte solution. J Chem Soc, Faraday Trans 2 Mol Chem Phys 83(8):1287-1306. https://doi.org/10. 1039/f29878301287

Schembre JM, Tang GQ, Kovscek AR (2006) Wettability alteration and oil recovery by water imbibition at elevated temperatures.

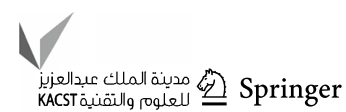


J Petrol Sci Eng 52(1-4):131-148. https://doi.org/10.1016/j. petrol.2006.03.017

Yousef AA, Liu J, Blanchard G, Al-Saleh S, Al-Zahrani T, Al-Tammar H, Al-Mulhim N (2012) Smart water flooding: industry's first field test in carbonate reservoirs, SPE-159526 presented at the SPE annual technical conference and exhibition held in San Antonio, Texas, USA, 8-10 October, ISBN: 9781622764150

Zaeri MR, Hashemi R, Shahverdi H, Sadeghi M (2018) Enhanced oil recovery from carbonate reservoirs by spontaneous imbibition of low salinity water. Petrol Sci 15(3):564-576. https://doi.org/10. 1007/s12182-018-0234-1
Zekri AY, Khalifi MJ, Attar H, Ghannam M (2020) Modification of Gulf seawater for possible use in improving oil recovery of carbonate formation: mechanism investigation. Int J Adv Sci Technol 29(3):12960-12976

Publisher's Note Springer Nature remains neutral with regard to jurisdictional claims in published maps and institutional affiliations. 